\title{
The Role of Soft Skills for Innovation at the SME Sector in Malaysia
}

\author{
Md Atiqur Rahman Sarker \\ PhD Research Fellow, Department of Business Administration \\ International Islamic University Malaysia, Box No. 10, 50728, Kuala Lumpur Malaysia \& \\ Assistant Professor, Department of Business Administration, East West University, \\ Bangladesh \\ E-mail: sarker.limon@gmail.com
}

Tariq Salameh Albluwi

PhD Research Fellow, Department of Business Administration

International Islamic University Malaysia

Box No. 10, 50728, Kuala Lumpur Malaysia

E-mail: tariq.bluwi@gmail.com

Received: June 5, $2021 \quad$ Accepted: July 14, $2021 \quad$ Published: July 14, 2021

doi:10.5296/jmr.v13i3.18839

URL: https://doi.org/10.5296/jmr.v13i3.18839

\begin{abstract}
Small and Medium Enterprise (SME) is booming in Malaysia and this sector also has many challenges. SME becomes sustainable and successful venture when the innovation and creativity are considered largely in doing the business. Soft skills are essential in this regard since it requires human relations in every business transaction. The objective of this research is to explore the role of various soft skills and their relations with innovation in the SME sector in Malaysia. For the methodology, the research used the inductive approach by performing six In-depth Interviews following Yin (2003). The results of this research have identified that communication, teamwork, leadership, critical thinking, positive attitudes, flexibility, and adaptability are the most used soft skills that help the entrepreneurs to be innovative and being successful in SME sectors in Malaysia. The results of this study will help the entrepreneurs in Malaysia to understand the essential soft skills for them to push towards innovative results. This one of the few qualitative research that comprehensively explores the relation between soft skills and innovation in Malaysia.
\end{abstract}

Keywords: Soft Skills, Innovation, SME, Malaysia 


\section{Introduction}

Innovation in Small and Medium Enterprise (SME) offers competitive advantage and distinctiveness for sustainable development of the economy, which includes the acquisition, dissemination and implementation of new and existing knowledge (Gault, 2018; Quintane, et al., 2011). Innovation fosters prosperity and growth of the business by stimulating employment and increasing wages that witness a higher productivity rate (Gault, 2018; Johnson, 2001). When a business offers innovative products and services, the organization has more propensity to survive and expand in the market. Innovation as the conversion of knowledge for implementation of new products, services or processes, an original marketing method or a new organizational method in business practice, workplace organizations or external relations (Allameh, 2018). Innovation in SME is also needed for growth and sustainability. If the entrepreneurs have the capacity to generate new ideas, then it makes the business distinct from others.

Innovation is fostered by one's ability to gather information, insights from experiences, and active networking skills (Gault, 2018). Thus, entrepreneurs need to have the skills of communication, critical thinking, time management and teamwork. These skills are recognized as soft skills. Soft skills are the social skills that include both personal qualities and interpersonal skills of an individual for emotional intelligence (Taylor, 2016). When employees possess soft skills, then the person can innovate new ideas and concepts for a better solution (Afroze, et al., 2019; Sarker, et al., 2019; Zaman, et al., 2018).

As soft skills promote new ideas, entrepreneurs should have soft skills for better success. However, soft skills are often overlooked at work, though soft skills have an essential role play on a day-to-day operation. Therefore, this study investigates the relationship between soft skills and innovation in the SME sector in Malaysia. The objective of this research is as follows

- To explore the role of various soft skills and their relations with innovation in the SME sector in Malaysia

\section{Theoretical background}

Soft skills have been a subject of life-long learning that have application in every aspect of life. Personal development of individuals gets enabled and enhanced through the development of soft skills (Gibb, 2014). Soft skills include personal accountability, strong work ethics, positive attitudes, self-motivation, the degree of collaboration, interpersonal skill, conflict resolution, negotiation skill, people's adaptability and flexibility, the clarity of communication, creative thinking, and the ability of coaching and mentoring etc. (Afroze, et al., 2019; Sarker, et al., 2019; Taylor, 2016; Zaman, et al., 2018). Learning the success of soft skills influences individual behavior both in social and professional life (Gibb, 2014; Zaman, et al., 2018). Soft skills practice has an impact on developing social skills as well as professional competency.

On the other hand, innovation has a wide variety of definitions (Witell et. al, 2015). The debate of a proper definition of innovation has been going on for almost a century 
(Schumpeter, 1934). This debate is due to innovation could be defined differently depending on the context it is in (De Vries et. al, 2016). Additionally, more than $70 \%$ of articles on innovation do not define innovation, and almost $24 \%$ define it in general (De Vries et. al, 2016). In this research, the fittest definition of innovation to the context is the definition provided by the Oslo Manual: An innovation is the implementation of a new or significantly improved product (good or service), or process, a new marketing method, or a new organizational method in business practices (Gault, 2018). There are three characteristics of innovation. The first which is Duplicability, this means that after having an innovative product/service/solution, it should be able to replicate the innovation in a new context taking into consideration. This is due to that the innovation is in the knowledge. The second characteristic is that it should be new in the context, generally if it is not new in the context then it is imitating not innovating. Finally, the innovation should have some usefulness otherwise, it is just as waste of time (Quintane, et al., 2011). Johnson (2001) has stated that innovation is crucial for entrepreneurial success. Critical thinking, problem-solving and taking rational decision are considered as soft skills which helps someone to be innovative (Afroze, et al., 2019; Taylor, 2016). Innovation in entrepreneurship is essential. Someone working as an entrepreneur must have the soft skills since these will enable the person to come up with creative ideas which have local demands for growth and sustainability of the business (Gault, 2018). Therefore, further research is done to relate soft skills and innovation.

\section{Method}

The research methodology for this study is qualitative in nature where exploratory case study approach has been considered. Six cases have been considered in this study to explore the relationship between soft skill and innovation for doing SME business in Malaysia. Data has been collected from six Malaysian entrepreneurs doing business in six different SME sectors. Entrepreneurs have been interviewed between January and February of 2021. The respondents are chosen from personal network and all of them are having 2 to 5 -year business experiences. This study makes description through fieldworks (semi-structured face to face interview). It follows interpretivism paradigms. The interpretivism paradigm means naturalistic ways of collecting data such as in-depth interviews, focus group discussions and observations (Saunders, et al., 2012; Yin, 2003).

All the interviews were tape-recorded with the consent of respondents and the issues discussed are transcribed verbatim and cross-checked by both researchers for data accuracy. At the same time, the transcriptions of all interviews have been cross checked by the interviewees. Since this study is conducted in a small scale, no software has been used rather interview data have been coded manually by the researchers. The nature of the data analysis is deductive, and it follows a predetermined structure guided by experts. Common themes in each question are identified and it concludes the influence of soft skills on innovation in a synthesize manner. Then, conceptually codes have been assigned from literature review to organize the data so it gets easier to create a labeling of the collected data. The process recommended by Yin (2003) has been followed to do the analysis which is highlighted as Verbatim $>$ Coding $>$ Data Categorization $>$ Developing Theme $>$ 
Interpretation.

\section{Results}

This part of the study explains the roles of practicing soft skills to come up with innovative ideas in SME sectors in Malaysia. All the participants are entrepreneurs and have academic backgrounds in business administration. They have mentioned the advantages of being entrepreneurs and their driving motives to work in the SME field. The participants acknowledge the necessity of having soft skills, and they have also discussed how those soft skills help them to be successful and have a smooth business operation. From the interviews, it has been identified that communication, teamwork, leadership, critical thinking, positive attitudes, flexibility, and adaptability are the most commonly used soft skills that help the entrepreneurs to be innovative and being successful in SME sectors in Malaysia. However, the findings of the study are discussed theme-wise below.

\subsection{Theme One: Participants' knowledge and views about soft skills, innovation, and SME}

Both participants have basic knowledge of soft skills, innovation and SME, and they have acknowledged that these are inter-related. Doing SME business is a passion and all the participants want to be financially independent and empowered. Participant one (P1) has expressed that,

"To be financially free. We thought that we spend too much time being an employee and enough is enough that is the time because we had this dream long time back but we were hesitating to bring it to the real life".

Coincidentally, all the participants worked as employee before, and they have started their own venture after having practical job experiences. They mentioned that soft skills are human skills which help them to maintain networking and connection with stakeholders. Participant two (P2) said that,

"soft skills are more inter-personal skills like communication, leadership, creative thinking etc.".

The participants of this study also have good knowledge about the concept and importance of innovation and SME. P1 stated that,

"innovation means being creative and unique that make the business different from others. SME is not like the company with wide variety of products and services. Thus SME needs to be unique which is possible only through innovation".

Third participant (P3) and fourth participant (P4) have emphasized during their interviews on the importance of innovation for the success of SME in Malaysia. Fifth participant (P5) strongly mentioned that,

"Malaysia is growing faster with economic development and it is now the business hub for global trade. Malaysian government is offering business incubators in different cities for the entrepreneurs that encourages new ideas".

Sixth participant (P6) has mentioned the same ideas as stated by P2. P6 also highlighted 
on product diversity through innovation. Thus innovation in SME is highly recommended.

\subsection{Theme Two: Types of soft skills practiced in SME}

As mentioned earlier, soft skills can be demonstrated in a wide variety of ways. There are multiple types of soft skills that can differ in importance depending on the type of business one is doing. The participants of this research are experiencing totally six different kinds of businesses (Trading, Sports Coaching, Consulting, Event Management) which resulted in focusing on different kinds of soft skills. Time-management is one of the soft skills that are very crucial when it comes to SMEs. Unlike big companies, a simple miss-up in the time schedule may lead to certain consequences. P2 have learned this in the hard way and clearly mentioned the importance of time management saying

"in terms of skills other than communication, it's the time-management, I am pretty good on it now. But previously I was like 30 minutes late, then I reduced late 15 then now I am on time that I learn the value of time over the years".

Another soft skill that stood out in this research is the intuition or "gut choices". P1 discussed that intuition is really important in doing small businesses that sometimes if the whole world is pointing towards a certain direction and your intuition is telling you the opposite you must follow your gut. P3 also mentioned about the importance of intuition by saying:

"decision making is not totally based on scientific facts... no I would say $90 \%$ it based on your intuition".

Although all the participants had different soft skills to focus on but also, they had few similar soft skills that they found important. The first common skill mentioned by all the participants is communication. Everyone in the interview addressed communication but from different perspectives: internal and external communications. When dealing with small businesses, reaching the right people in the right way is vital and this is what the participants found in the hard way. P3 and P5 had problems in the language barrier although all the participants are local and can speak the Malay language but had language and cultural barriers in dealing with foreign clients and customer from different races such as Indian and Chinese. P6 mentioned

"So language is some of the barriers I face. And you have to understand the content and the protocol while taking with public official"

addressing the right people in the right way can change the outputs of meetings exponentially. P4 addressed communication in the matter of the language and culture itself. P1 had huge problem in delivering the idea to customers because he did not speak the language and did not understand the culture properly. He mentioned

"we need a local front end to be at the marketing and sale job so they can speak the same language and they can really negotiate with them and educate the customers".

Another common appreciated soft skill all entrepreneurs found handy was leadership skills. Since leadership is wide topic and have different parts in it depending on the business all 
the participants addressed leadership in different areas. P1 discussed about opportunistic leaders and their importance by saying

"successful entrepreneur, manager, and leaders or whatever have those who can change the challenge into opportunity."

Since P3 have faced a lot of challenges, P3 found this kind of leadership is essential in his kind of business. Also some other skills in leadership like managerial skills and knowledge was stated by P5,

"managerial skills so you have to follow and stick to the managerial knowledge or skills that any entrepreneur has to have so for example to say hot to make a business plan how to build your marketing plan all these things is really push up for the business".

P1 addressed leadership as its basic skill and its importance. P2 started addressing the problem by saying

"I don't know how to behave like CEO and I am the first time"

and mentioned couple of problems that he faced due to lack of managerial skills including how to deal with stubborn employees.

P3 finally concluded some important soft skills as a final remark by saying

"First factor is actually how you strategize your business.... second how you manage financial issues... three, how you manage your team member... four, how you want you to position yourself."

\subsection{Theme Three: The role of soft skills practice for innovation in SME}

It was clearly mentioned earlier that the importance of soft skills in the success of SMEs. The participants also talked about innovation and how it is essential in the modern market. Innovation plays a substantial role in ensuring the sustainability of the company. P1 mentioned

"Innovation also aah it will make you different in the market because you will be offering different solutions more creative products inside your system".

P3 also continues to talk about on who should be innovative by saying

"for the time being its mandatory for all. And I think it is also based on facts and on my readings and experience with other experts as well".

P3 supported this claim as well, and mentioned competitive advantage by saying

"So better, for this current economy, to grow well, you must have stuff better than you".

In order to connect the dots, the participants were asked about how innovation and soft skills go hand in hand. P4 and P6 have addressed the matter pretty straight forward and supported the relationship between soft skills practices and innovation in doing business. P4 claimed by saying 
"Significant relationship. The more skills you are enjoying or practicing the more creativity output you will have".

This shows that soft skills are enablers for creativity and innovation. He added later on as well about competitive advantage by saying,

"More difficult for SMEs now to compete that is why to have such kind of innovation will give you some sort of competitive advantage".

P2 addressed this topic in a different matter by stating the admiration of personal value and combining it with the company value by saying,

"When you have the PV (Personal Value) = company value, the company will grow better."

By doing so, this will inspire the entrepreneurs to perform better and become more creative and thus more innovative.

\subsection{Theme Four: Different Soft Skills Challenges in SMEs}

Any business can face different kinds of challenges. These challenges might have various reasons. The participants of this research faced a couple of challenges due to the lack of soft skills practice. The skills of understanding culture and the circumstances around is critical. P5 faced considerable problems in opening the business at first due to a lack of understanding of the situation and culture. P1 mentioned that since not understanding the context of Malaysia had many consequences,

"one of the challenges also we the procedures the legal procedures in Malaysia. so the context of Malaysian in terms of doing business as a foreigner.... we spent around three months afterword to open a bank account for example".

He, later on, replied when asked if he knew the context will he change his mind. The answer was

"Off course, we will change our mind, maybe we will target another country or sector.".

P2 talked about the topic of understanding the context in a different way. P2 did not at first understand the segmentation and characteristics of customers he mentioned,

"the market segmentation. We want to define what we sell to whom... It was very hard for me because every player from different ages have different characteristics. So, adopt people's different thing is difficult for me in play".

Both participants also faced some problems due to not being able to deal with tough coworkers, employees and partners. As a matter of fact, the lack of some soft skills lead to a break in partnership is some cases. P6 talked about this problem saying

"I thought that my partner had the enough experience to run the company... unfortunately he did not complete any deal before starting to work here... Few more challenge came because my partner left me after five months". 
This problem could have been avoided easily if the team work skill was there. P4 also addressed some difficulties dealing with team member production and said

"I had 7-8 people and you need team members. But they come and move out, something happens like that".

Thus, lack of soft skills practice lead to many challenges for the entrepreneurs to run the business.

\section{Discussion}

The first soft skill stated by entrepreneurs was the time management skill. Time management, in general, refers to actions that imply an efficient use of time in order to increase production and reduce stress. "Planning behavior" is a prevalent component in time management conceptualizations (Claessens et al., 2007). Original ideas are generally located far afield from the original problem or concept. This remoteness necessitates time; it takes time to travel from one notion to the next, as well as to locate the distant associate (Zampetakis, Bouranta \& Moustakis, 2010).

Another soft skill the entrepreneurs mentioned affect innovation was intuition or gut feeling. It is defined as that which allows for rapid decision-making based on patterns detected via experience' Based on one's sensibility, one can sense how something is or how something is related to another (Taura \& Nagai, 2013). Many authors have addressed the importance of intuition or gut feeling in complex decision-making (Duggan, 2013; Gigerenzer, 2008; Gladwell, 2006; Olli 2013).

A final common skill stated by the participants was the leadership. Leaders that are dependable and committed are typically vital in driving innovation and stimulating critical thinking and problem solutions (Martensen et al., 2007). Agolla and Van Lill (2017) also stated that the support of the management and colleagues, which will give inspiration to innovation. There are different kinds of leadership that helps innovative outcome like Transformational leadership (Jia et al., 2018), Participative Leadership (Miao et al., 2014), and Supportive Leadership (Tung \& Yu, 2016).

\section{Limitations and Future Implications}

Every research has its limitations. This research was conducted by interviewing six participants only. In order to get better results, more interviews can be conducted in the future. The research was also conducted in Malaysia from the SME context of Kuala Lumpur area. Thus, the results cannot be generalized for whole Malaysia. Therefore, increasing the geographical scope is important for future studies. All the participants were interviewed in English which was not their mother tongue. Thoughts might have been expressed wrongly, therefore future interviews could be done through the mother tongue.

\section{Conclusion}

This research explores the relationship between soft skills and innovation and how combining the two aspects will benefit the SMEs performance. The research started by stating some theoretical background that supports the proposed theory. The researchers 
conducted interviews with six participants. All the participants showed the importance of having both innovation and soft skills in the business of SMEs. They also shared stories of how lacking some soft skills prevented them from doing better and innovate properly. The role of soft skill practices is clearly reflected in positive manner for SME performance. It is also recommended that soft skills must be developed by the managers and entrepreneurs to manage both employees and customers.

Therefore, the findings of this study is contributing to the fields of entrepreneurship, innovation, SME and soft skills development. It also draws the attention of policy makers and educational institutions to emphasize more on developing soft skills among students and employees at work. Thus, it will have a positive influence on developing innovative ideas and solutions for growth and sustainability in a competitive global market. The findings of this study will also influence the managers and entrepreneurs to practice soft skills for innovation in the future. This study had followed an integrated process of relating different soft skills with innovation which is a new dimension for SME development.

\section{References}

Afroze, R., Eva, T. P., \& Sarker, M. A. R. (2019). A Study On Employability Skills Of Engineering Graduates. Journal of Intercultural Management, 11(3), 21-44. https://doi.org/10.15405/epsbs.2019.08.03.72

Agolla, J. E., \& Van Lill, J. B. (2017). Insights into Kenya's public sector innovation: The case of managers. International Journal of Innovation Science, 9(3), 225-243. https://doi.org/10.1108/IJIS-11-2016-0049

Allameh, S. M. (2018). Antecedents and consequences of intellectual capital: The role of social capital, knowledge sharing and innovation. Journal of Intellectual Capital, 19(5), 858-874. https://doi.org/10.1108/JIC-05-2017-0068

Claessens, B. J. C., van Eerde, W., Rutte, C. G., \& Roe, R. A. (2007). A review of the time management literature. Personnel Review, 36(2), 255-276. https://doi.org/10.1108/00483480710726136

De Viries H., Bekkers V., Tummers L. (2016). Innovation in the Public Sector: A Systematic Review Future Research Agenda. Public Administration, 94(1), 146-166. https://doi.org/10.2139/ssrn.2638618

Duggan, W. (2013). Strategic intuition: The creative spark in human achievement. New York, NY: Columbia University Press.

Gault, F. (2018). Defining and measuring innovation in all sectors of the economy. Research Policy, 47, 617-622, https://doi.org/10.1016/j.respol.2018.01.007

Gibb, S. (2014). Soft skills assessment: theory development and the research agenda. International Journal of Lifelong Education, 33(4), 455-471. https://doi.org/10.1080/02601370.2013.867546 
Gigerenzer, G. (2008). Gut feelings: The intelligence of the unconscious. London: Penguin Books

Gladwell, M. (2006). Blink: The power of thinking without thinking. London: Penguin Books

Jia, X., Chen, J., Mei, L., \& Wu, Q. (2018). How leadership matters in organizational innovation: a perspective of openness. Management Decision, 56(1), 6-25. https://doi.org/10.1108/MD-04-2017-0415

Johnson, D. (2001). What is innovation and entrepreneurship? Lessons for larger organizations. Industrial and Commercial Training, 33(4), 135-140. https://doi.org/10.1108/00197850110395245

Martensen, A., Dahlgaard, J. J., Park-Dahlgaard, S. M., \& Grønholdt, L. (2007). Measuring and diagnosing innovation excellence - Simple contra advanced approaches: A Danish study. Measuring Business Excellence, 11(4), 51-65. https://doi.org/10.1108/13683040710837928

Miao, Q., Newman, A., \& Huang, X. (2014). The impact of participative leadership on job performance and organizational citizenship behavior: Distinguishing between the mediating effects of affective and cognitive trust. International Journal of Human Resource Management, 25(20), 2796-2810. https://doi.org/10.1080/09585192.2014.934890

Olli, H. (2013). Decision Makers' Use of Intuition at the Front End of Innovation (Doctoral). Aalto University.

Quintane, E., Casselman, R. M., Reiche, B. S., Nylund, P. A. (2011). Innovation as a knowledge-based outcome. Journal of Knowledge Management, 15(6), 928-947, https://doi.org/10.1108/13673271111179299

Schumpeter, J. (1934). Theories of economic development. (Cambridge, MA).

Sarker, M. A. R., Hashim, J. B., Haque, A., Sarif, M. S. Bin, \& Juhdi, N. B. (2019). Soft Skills Practiced by Managers for Employee Job Performance in Ready Made Garments (RMG) Sector of Bangladesh. Journal of International Business and Management, 2(4), 1-15. Retrieved from https://rpajournals.com/jibm. ISSN: 2616-4655

Saunders, M., Lewis, P. and Thornhill, A. (2012). Research Methods for Business Students. 6th edition, Pearson Education Limited.

Taylor, E. (2016). Investigating the perception of stakeholders on soft skills development of students: Evidence from South Africa. Interdisciplinary Journal of E-Skills and Lifelong Learning, 12(1), 1-18. https://doi.org/10.28945/3412

Toshiharu Taura \& Yukari Nagai (2017) Creativity in Innovation Design: the roles of intuition, synthesis, and hypothesis, International Journal of Design Creativity and Innovation, 5(3-4), 131-148. 
Tung, F. C., \& Yu, T. W. (2016). Does innovation leadership enhance creativity in high-tech industries? Leadership and Organization Development Journal, 37(5), 579-592. https://doi.org/10.1108/LODJ-09-2014-0170

Yin, R.K. (2003). Case Study Research: Design and Methods. Sage. Thousand Oaks, California.

Witell, L., Snyder, H., Gustafsson, A., Fombelle, P., Kristensson, P (2015). Defining service innovation: A review and synthesis. Journal of Business Research, https://doi.org/10.1016/j.jbusres.2015.12.055

Zaman, L., Sarker, A.R, and Akhter, N. (2018). Study on Practice of Soft Skill among the Workforce: A Case from Ready Made Garment (RMG) Industry of Bangladesh. International Journal of Asian Social Science, 8(10), 808-8018, ISSN: 2226-5139. https://doi.org/10.18488/journal.1.2018.810.808.818

Zampetakis, L., Bouranta, N., \& Moustakis, V. (2010). On the relationship between individual creativity and time management. Thinking Skills And Creativity, 5(1), 23-32. https://doi.org/10.1016/j.tsc.2009.12.001 